\title{
Digestibilidade aparente de rações contendo complexo enzimático para tilápia-do-nilo
}

[Apparent digestibility of diets containing enzyme supplement for Nile tilapia]

\author{
I.G. Guimarães ${ }^{1}$, D.R. Falcon ${ }^{2}$, D. Schich ${ }^{3}$, M.M. Barros ${ }^{4}$, L.E. Pezzato ${ }^{4 *}$ \\ ${ }^{1}$ Aluno de pós-graduação - FMVZ-UNESP - Botucatu, SP \\ ${ }^{2}$ Aluno pós-graduação - CAUNESP-UNESP - Jaboticabal, SP \\ ${ }^{3}$ Aluno de graduação - FMVZ-UNESP - Botucatu, SP \\ ${ }^{4}$ Faculdade de Medicina Veterinária e Zootecnia - UNESP \\ Caixa Postal 560 \\ 18618-000 - Botucatu, SP
}

\begin{abstract}
RESUMO
Avaliou-se a digestibilidade aparente de cinco rações isoproteicas e isoenergéticas contendo $0 ; 0,1 ; 0,2 ; 0,3$ e $0,4 \mathrm{~g}$ do complexo enzimático Bioenzimaplus (lipase, protease e carboidrase)/ $\mathrm{kg}$ de ração na alimentação da tilápia-do-nilo. Foram utilizados 100 peixes distribuídos em cinco aquários de alimentação e cinco aquários de coleta de fezes. Os cinco tratamentos foram arranjados em delineamento inteiramente ao acaso com cinco repetições. Houve efeito linear de tratamento sobre a digestibilidade aparente (CDa) para proteína bruta e extrato etéreo. O CDa da proteína bruta e do extrato etéreo variaram de $81,60 \%$ a $84,93 \%$ e de $74,19 \%$ a $82,69 \%$, respectivamente. Para carboidrato e energia bruta, o maior nível de suplementação resultou em maior $\mathrm{CDa}, 57,85 \%$ e $63,78 \%$, respectivamente $(\mathrm{P}<0,05)$. Não foi observada diferença entre tratamentos no CDa da matéria seca, apresentando valores de $49,47 \%$ a 58,55\%. A inclusão de complexo enzimático - lipase, protease e carboidrase - em dietas para tilápia-do-nilo melhorou a digestibilidade da proteína, do extrato etéreo, do carboidrato e da energia das rações.
\end{abstract}

Palavras-chave: peixe, enzima, valor nutritivo, coeficiente de digestibilidade, Oreochromis niloticus

\begin{abstract}
Apparent digestibility $(A D C)$ of five isoproteic and isoenergetic diets containing 0, 0.1, 0.2, 0.3, and $0.4 \mathrm{~g} / \mathrm{kg}$ of enzymatic complex BioEnzimaplus (lipase, protease, and carbohydrase) for Nile tilapia was evaluated. A hundred fish were randomly assigned in five feeding aquaria, and five collecting feces ones. Treatments were composed by five enzymatic complex levels arranged in a completely randomized design in five repetitions. Significant differences $(P<0.05)$ were observed with the inclusion of enzymatic complex in the diets for ADC of crude protein and fat (linear effect). ADC of crude protein and fat varied from $81.60 \%$ to $84.94 \%$ and $74.19 \%$ to $85.69 \%$, respectively. The highest enzyme supplementation level showed better digestibility values for carbohydrate and gross energy (57.85\% and $63.78 \%$, respectively). No difference was observed for ADC of dry matter showing values between $49.47 \%$ and $58.55 \%$. The use of enzymes in Nile tilapia diets improved the digestibilities of protein, fat, carbohydrate, and gross energy digestibility.
\end{abstract}

Keywords: fish, enzyme, nutritive value, digestibility coefficients, Oreochromis niloticus

\section{INTRODUÇÃO}

A análise química é o ponto inicial para determinação do valor nutritivo de um ingrediente ou ração (Maynard e Loosly, 1966). Segundo Pezzato et al. (2004), o conhecimento do coeficiente de digestibilidade dos alimentos e dos nutrientes permite a formulação de rações que melhor atendam as exigências nutricionais dos peixes, evitando tanto a sobrecarga fisiológica quanto a ambiental.

Recebido em 28 de janeiro de 2009

Aceito em 17 de novembro de 2009

*Autor para correspondência (corresponding author)

E-mail: epezzato@fca.unesp.br 
Para obter alta eficiência produtiva a custos baixos, é necessário melhoria na utilização das dietas e maior variedade de ingredientes que possam ser utilizados nas formulações. Os produtores de ração, assim como os produtores de peixe, são altamente dependentes do custo dos ingredientes, bem como do seu valor nutritivo. Nesse sentido, pesquisas têm procurado solucionar estes problemas por meio do estudo do valor nutritivo de ingredientes, assim como de aditivos alimentares que possam melhorar o valor nutricional desses ingredientes ou das dietas por eles compostas, reduzindo também a eutrofização do meio.

A utilização de enzimas exógenas como aditivo alimentar tem por objetivo aumentar a disponibilidade dos nutrientes presentes nos alimentos (Yin et al., 2001). Os aditivos enzimáticos não possuem função nutricional direta, mas auxiliam o processo digestivo, melhorando a digestibilidade dos nutrientes presentes na dieta.

Enzimas são proteínas globulares, de estrutura terciária ou quaternária, que agem como catalisadores biológicos, aumentando a velocidade das reações químicas no organismo, sem serem elas próprias alteradas nesse processo (Champe e Harvey, 1989). São altamente específicas para os substratos e dirigem todos os eventos metabólicos. As enzimas digestivas têm um sítio ativo que permite que elas atuem na ruptura de determinada ligação química sob condições favoráveis de temperatura, $\mathrm{pH}$ e umidade (Penz Júnior, 1998).

No mercado, encontram-se vários tipos de enzimas com substratos de ação diferentes, assim como complexos enzimáticos compostos por diversas enzimas. Dentre as principais funções da suplementação com enzimas exógenas nas rações dos animais monogástricos, destacam-se: a remoção ou destruição de fatores antinutricionais presentes nos alimentos de origem vegetal, o aumento da digestibilidade das dietas, a potencialização da ação das enzimas endógenas e a redução da poluição ambiental causada pela excreção de nutrientes (Garcia et al., 2000).
Esses aditivos alimentares têm sido incorporados às rações de aves e suínos com o propósito de melhorar o desempenho $\mathrm{e}$, com isso, sua rentabilidade. No entanto, são escassas as informações sobre o efeito de enzimas exógenas na digestibilidade das frações nutritivas da ração em peixes. A presente pesquisa teve por objetivo avaliar o efeito de níveis crescentes de complexo enzimático sobre a digestibilidade em juvenis de tilápia-do-nilo.

\section{MATERIAL E MÉTODOS}

A pesquisa foi realizada na UNESP Universidade Estadual Paulista, no Laboratório de Nutrição de Organismos Aquáticos, do Departamento de Nutrição Animal da Faculdade de Medicina Veterinária e Zootecnia, Botucatu, São Paulo.

Foram avaliados os coeficientes de digestibilidade aparente $(\mathrm{CDa})$ da matéria seca, da proteína bruta, do extrato etéreo, do carboidrato e da energia bruta de uma ração, à qual houve a adição de níveis crescentes do complexo enzimático Bioenzimaplus, composto por carboidrase, protease e lipase. As rações experimentais foram formuladas de modo a apresentarem-se isoenergéticas, $3200 \mathrm{kcal} \mathrm{ED} / \mathrm{kg}$ de ração, e isoproteicas, 33,0\% PB e 30,26\% PD. Foram avaliados cinco tratamentos, sendo o controle a ração sem suplementação, e os demais contendo 0,$1 ; 0,2 ; 0,3$ e $0,4 \mathrm{~g}$ do complexo enzimático $/ \mathrm{kg}$ de ração, em delineamento inteiramente ao acaso, com cinco repetições.

Para o preparo das rações, empregaram-se ingredientes energéticos e proteicos de origem vegetal, cuja formulação e características nutricionais encontram-se nas Tab. 1 e 2, respectivamente. No sentido de mensurar os coeficientes de digestibilidade aparente (CDa), as rações receberam $0,1 \%$ de óxido de crômio-III $\left(\mathrm{Cr}_{2} \mathrm{O}_{3}\right)$, conforme metodologia proposta por Bremer Neto et al. (2005). As dietas foram peletizadas e secas em estufa com ventilação forçada a $55,0^{\circ} \mathrm{C}$ por 24 horas, e os péletes desintegrados de modo a se apresentarem com diâmetro de 4,0mm. 
Digestibilidade aparente de rações...

Tabela 1. Composição percentual das rações experimentais (base na matéria natural) para tilápia-do-nilo

\begin{tabular}{lccccc}
\hline & \multicolumn{5}{c}{ Tratamento $^{1}$} \\
\cline { 2 - 6 } Ingrediente (\%) & $0,0 \mathrm{CE}$ & $0,1 \mathrm{CE}$ & $0,2 \mathrm{CE}$ & $0,3 \mathrm{CE}$ & $0,4 \mathrm{CE}$ \\
\hline Milho & 18,42 & 18,41 & 18,40 & 18,39 & 18,38 \\
Farelo de soja & 66,00 & 66,00 & 66,00 & 66,00 & 66,00 \\
Farelo de trigo & 9,00 & 9,00 & 9,00 & 9,00 & 9,00 \\
Complexo enzimático & 0,0 & 0,01 & 0,02 & 0,03 & 0,04 \\
DL-metionina & 0,13 & 0,13 & 0,13 & 0,13 & 0,13 \\
Fosfato bicálcico & 3,30 & 3,30 & 3,30 & 3,30 & 3,30 \\
Óxido de crômio & 0,1 & 0,1 & 0,1 & 0,1 & 0,1 \\
Óleo de soja & 2,40 & 2,40 & 2,40 & 2,40 & 2,40 \\
Supl. vit/min & 0,50 & 0,50 & 0,50 & 0,50 & 0,50 \\
Vitamina C & 0,03 & 0,03 & 0,03 & 0,03 & 0,03 \\
Sal comum & 0,10 & 0,10 & 0,10 & 0,10 & 0,10 \\
BHT & 0,02 & 0,02 & 0,02 & 0,02 & 0,02 \\
\hline Total & 100,00 & 100,00 & 100,00 & 100,00 & 100,00 \\
\hline
\end{tabular}

0,0 a 0,4 de complexo enzimático (CE)/kg de ração.

${ }^{2}$ Suplemento vitamínico e mineral (Supremais) - níveis de garantia por kg do produto= vit.A: $1.200 .000 \mathrm{UI}$; vit.D3: 200.000UI; vit.E: $12.000 \mathrm{mg}$; vit.K3: $2.400 \mathrm{mg}$; vit.B1: $4.800 \mathrm{mg}$; vit.B2: $4.800 \mathrm{mg}$; vit.B6: 4.000mg; vit.B12: $4.800 \mathrm{mg}$; ac. fólico: $1.200 \mathrm{mg}$; pantotenato Ca: $12.000 \mathrm{mg}$; vit.C: $48.000 \mathrm{mg}$; biotina: $48 \mathrm{mg}$; colina: 65.000mg; niacina: 24.000mg; Fe: $10.000 \mathrm{mg}$; Cu: 600mg; Mn: 4.000mg; I: 20mg; Co: 2mg; Se: $20 \mathrm{mg}$. BHT $=$ butil hidroxi tolueno, antioxidante.

Tabela 2. Composição químico-bromatológica das rações experimentais para tilápia-do-nilo

\begin{tabular}{lccccc}
\hline & \multicolumn{4}{c}{ Tratamento } \\
\cline { 2 - 5 } & $0,0 \mathrm{CE}$ & $0,1 \mathrm{CE}$ & $0,2 \mathrm{CE}$ & $0,3 \mathrm{CE}$ & $0,4 \mathrm{CE}$ \\
\hline Proteína bruta (\%) & 33,05 & 33,05 & 33,05 & 33,05 & 33,05 \\
Proteína digestível (\%) & 30,26 & 30,26 & 30,26 & 30,26 & 30,26 \\
Energia digestível & 3120 & 3120 & 3120 & 3120 & 3120 \\
Fibra bruta (\%) & 5,07 & 5,07 & 5,07 & 5,07 & 5,07 \\
Lipídio total (\%) & 4,23 & 4,23 & 4,23 & 4,23 & 1,05 \\
Cálcio (\%) & 1,05 & 1,05 & 1,05 & 0,61 & 1,05 \\
Pisp (\%) & 0,61 & 0,61 & 0,61 & 0,61 & 0,61 \\
Metionina (\%) & 0,61 & 0,61 & 0,61 & 1,28 & 1,28 \\
Treonina (\%) & 1,28 & 1,28 & 1,28 & 1,94 \\
Lisina (\%) & 1,94 & 1,94 & 1,94 & 1,94 \\
\hline
\end{tabular}

0,0 a 0,4 de complexo enzimático (CE)/kg de ração.

Para a alimentação dos peixes, foram utilizados cinco aquários de formato circular, com capacidade de $250 \mathrm{~L}$, e, para a coleta de fezes, foram utilizados cinco aquários de formato cônico, com capacidade de 300L. Esses aquários possuíam sistema de recirculação contínua de água, com filtro físico-biológico e temperatura controlada por meio de termostato.

Foram alojados 100 juvenis de tilápia-do-nilo, com peso médio de $100,0 \pm 10,0 \mathrm{~g}$, em seis tanques-rede, com 20 peixes/tanque-rede, de formato circular, confeccionados em tela plástica com malha de $1,50 \mathrm{~cm}$ entre nós. Os tanques-rede foram utilizados para abrigar os peixes e facilitar o manejo de alimentação e coleta de fezes, minimizando o estresse.

Durante o período experimental, a temperatura média da água dos aquários foi $26,0 \pm 0,5^{\circ} \mathrm{C}$; o pH 7,0 $\pm 0,5$; o oxigênio dissolvido $6,2 \pm 0,5 \mathrm{mg} / \mathrm{L}$, a dureza $5,9 \mathrm{mg} / \mathrm{L}$; a alcalinidade $13,0 \mathrm{mg} / \mathrm{L}$ e a amônia $\left(\mathrm{NH}_{3}\right)$ 147,0 $\mu \mathrm{g} / \mathrm{L}$, estando dentro da faixa de conforto recomendada para tilápia (Popma e Green, 1990).

Empregou-se a metodologia descrita por Pezzato et al. (2004), em que os peixes são arraçoados fora do sistema coletor de fezes. Os peixes mantidos durante o dia, nos aquários de 
alimentação, receberam refeições à vontade das $8 \mathrm{~h}$ até às $17 \mathrm{~h}$ e $30 \mathrm{~min}$, por meio de arraçoamento manual. Posteriormente, foram transferidos para os aquários de coleta de fezes, onde permaneceram até a manhã do dia subsequente. Esses tanques, dotados de sistema de coleta de fezes por gravidade, possibilitaram a obtenção do material para análise. Após o período de alimentação e de coleta de fezes, realizou-se a limpeza nos aquários, preparando-os para nova coleta (repetição). Foram necessários cinco dias de coleta de fezes (repetição/dia) para cada tratamento. Após a coleta, as fezes, desidratadas em estufa com ventilação forçada a $55,0^{\circ} \mathrm{C}$ por 48 horas, foram moídas e armazenadas a $20,0^{\circ} \mathrm{C}$.

As análises químico-bromatológicas dos alimentos, das rações e das fezes foram realizadas segundo o AOAC (Official..., 1995). As análises para determinação da concentração de crômio-III, das fezes e das rações foram feitas segundo Bremer Neto et al. (2005). O coeficiente de digestibilidade aparente foi calculado com base na fórmula proposta por Cho et al. (1985).

Os valores de porcentagem foram transformados pela expressão $y=\operatorname{arcsen} \sqrt{x / 100}$, sendo $x$ o valor da variável expresso em porcentagem. Para análise estatística, foi utilizado $\mathrm{o}$ pacote estatístico SAS/1995. Os dados foram submetidos à análise de variância e quando se observou diferença significativa, aplicou-se a análise de regressão. Usou-se, ainda, o teste Tukey para a comparação de médias, nível de
$5,0 \%$ de probabilidade, quando não se observou efeito significativo da regressão.

\section{RESULTADOS E DISCUSSÃO}

As médias dos CDa (\%) da proteína bruta (PB), matéria seca (MS), extrato etéreo (EE) e energia bruta $(\mathrm{EB})$ das rações com diferentes níveis do complexo enzimático encontram-se na Tab. 3.

O CDa para as frações PB e EE foram crescentes conforme a adição dos níveis de complexo enzimático. Os valores do $\mathrm{CDa}$ da $\mathrm{PB}$ observados foram similares àqueles obtidos por Vens-Cappell (1984) e Booth et al. (2002) em dietas práticas para truta e perca (Bydianus bydianus), respectivamente.

O CDa aumentou conforme foi adicionado o complexo enzimático à dieta. Isto pode ser atribuído à maior superfície de contato do substrato com a enzima e à consequente melhora da digestão dos carboidratos e lipídios associados à proteína da ração, disponibilizando o substrato para a ação das proteases do trato digestório do animal e do complexo multienzimático. Garcia et al. (2000) não observaram efeito da adição de complexo enzimático em dietas práticas à base de milho $\mathrm{e}$ soja para frangos de corte. A melhora na digestibilidade da proteína com a adição do complexo enzimático pode estar relacionada, ainda, com a degradação de algumas proteínas do farelo de soja que atuam como fatores antinutricionais (inibidores de protease), tornando esse alimento mais digestível para o animal (Salanova, 1996)

Tabela 3. Coeficientes de digestibilidade aparente (\%) da proteína bruta, extrato etéreo, matéria seca, energia bruta e carboidrato das rações com níveis crescentes de complexo enzimático para tilápia-do-nilo

\begin{tabular}{|c|c|c|c|c|c|c|c|}
\hline \multirow[t]{2}{*}{ Parâmetro } & \multicolumn{5}{|c|}{ Tratamento $^{1}$} & \multirow[t]{2}{*}{$\mathrm{CV} \%$} & \multirow[t]{2}{*}{ Regressão } \\
\hline & $0,0 \mathrm{CE}$ & $0,1 \mathrm{CE}$ & $0,2 \mathrm{CE}$ & $0,3 \mathrm{CE}$ & $0,4 \mathrm{CE}$ & & \\
\hline Matéria seca & $\begin{array}{c}49,47 \\
( \pm 5,30)\end{array}$ & $\begin{array}{c}58,55 \\
( \pm 3,12)\end{array}$ & $\begin{array}{c}55,95 \\
( \pm 2,99)\end{array}$ & $\begin{array}{c}57,31 \\
( \pm 1,83)\end{array}$ & $\begin{array}{c}58,39 \\
( \pm 3,90)\end{array}$ & 6,46 & NS \\
\hline Proteína bruta & $\begin{array}{c}81,60 \\
( \pm 2,50)\end{array}$ & $\begin{array}{c}83,07 \\
( \pm 1,68)\end{array}$ & $\begin{array}{c}84,50 \\
( \pm 1,18)\end{array}$ & $\begin{array}{c}85,76 \\
( \pm 1,45)\end{array}$ & $\begin{array}{c}84,93 \\
( \pm 2,26)\end{array}$ & 2,24 & $82,10+9,34 x$ \\
\hline Extrato etéreo & $\begin{array}{c}74,19 \\
( \pm 1,86)\end{array}$ & $\begin{array}{c}79,76 \\
( \pm 6,55)\end{array}$ & $\begin{array}{c}77,49 \\
( \pm 4,56)\end{array}$ & $\begin{array}{c}82,44 \\
( \pm 2,56)\end{array}$ & $\begin{array}{r}82,69 \\
( \pm 4,92)\end{array}$ & 5,58 & $75,38+19,57 \mathrm{x}$ \\
\hline Carboidrato & $\begin{array}{l}49,07 \mathrm{~b} \\
( \pm 5,20)\end{array}$ & $\begin{array}{l}58,37 \mathrm{a} \\
( \pm 2,21)\end{array}$ & $\begin{array}{l}52,54 \mathrm{ab} \\
( \pm 1,63)\end{array}$ & $\begin{array}{l}59,92 \mathrm{a} \\
( \pm 1,40)\end{array}$ & $\begin{array}{l}57,85 \mathrm{a} \\
( \pm 3,48)\end{array}$ & 5,61 & NS \\
\hline Energia bruta & $\begin{array}{l}54,93 \mathrm{~b} \\
( \pm 4,42)\end{array}$ & $\begin{array}{c}62,88 \mathrm{ab} \\
( \pm 2,59)\end{array}$ & $\begin{array}{l}61,35 \mathrm{ab} \\
( \pm 3,00)\end{array}$ & $\begin{array}{l}62,24 \mathrm{ab} \\
( \pm 1,71)\end{array}$ & $\begin{array}{r}63,78 \mathrm{a} \\
( \pm 3,40)\end{array}$ & 5,17 & NS \\
\hline
\end{tabular}

${ }^{1} 0,0$ a 0,4 de complexo enzimático $(\mathrm{CE}) / \mathrm{kg}$ de ração.

Valores na mesma linha seguidos por diferentes letras diferem entre si $(\mathrm{P}<0,05)$;

NS = não significativo; 
$\mathrm{r}^{2}=\mathrm{PB}=0,80 ; \mathrm{r}^{2} \mathrm{EE}=0,76$.

Os valores de CDa obtidos para a matéria seca e os obtidos com outras espécies de monogástricos relacionam-se à baixa capacidade dessas enzimas exógenas às flutuações de $\mathrm{pH}$ e ao ataque proteolítico das enzimas digestivas. Bedford (1995) salientou que enzimas exógenas devem agir sob as condições do trato digestório e que o grau de digestão do substrato deve ser significativo para promover maior digestibilidade e melhora no desempenho do animal.

É importante ressaltar que nem sempre a suplementação de enzimas digestivas proporciona resposta positiva. Para a enzima atuar, faz-se necessário que haja o substrato específico na dieta e a dosagem correta de enzimas e que a capacidade das enzimas ultrapasse as barreiras presentes no estômago baixo $\mathrm{pH}$ e ação das enzimas proteolíticas como a pepsina - e a temperatura à qual a ração é submetida durante o processo de peletização.

Quando comparadas à ração-controle, as rações que continham complexo enzimático (CE) proporcionaram maior digestibilidade dos carboidratos da dieta, principalmente nos níveis mais elevados de inclusão do CE, 0,3 e $0,4 \mathrm{~g}$ do complexo enzimático/kg de ração. Segundo Classen (1996), a adição de enzimas microbianas às dietas contendo alta proporção de cereais melhora a utilização dos carboidratos, porém deve-se considerar a estrutura central do polissacarídeo de interesse. Cavero (2004), em estudos realizados com pirarucu, observou que a adição de amilase exógena às dietas não melhorou o desempenho zootécnico devido à baixa taxa de metabolização da glicose plasmática. Esse autor concluiu que a maior digestibilidade dos carboidratos pode aumentar a digestibilidade da dieta sem, necessariamente, melhorar o desempenho zootécnico.

Os resultados obtidos nesta pesquisa (Tab. 3) confirmam os encontrados por Tung e Shiau (1991), quando concluíram que a tilápia-do-nilo digere mais eficientemente carboidratos complexos, como amido e dextrina, que monossacarídeos. Da mesma forma, Stone et al. (2003) obtiveram resultados similares com a perca (Bydianus bydianus), com aumento discreto na digestibilidade do amido de trigo quando adicionaram níveis crescentes de amilase às dietas.

Para a energia bruta, observou-se resposta similar à obtida para os carboidratos, isto é, o maior nível de enzima, $0,4 \mathrm{~g}$ de $\mathrm{CE} / \mathrm{kg}$ de ração, resultou em maior $\mathrm{CDa}$. Os valores de digestibilidade da energia bruta, entre 55,0 e $64,0 \%$, estão próximos aos obtidos por VensCappell (1984) e Booth et al. (2002). O aumento na digestibilidade da fração energética deve-se ao aumento na digestibilidade dos demais nutrientes da ração, proteína, lipídios e carboidratos, que podem ser utilizadas como fonte energética. Tal hipótese confirma os resultados de Classen (1996), que relatou correlação positiva entre a digestibilidade do amido e o aumento da digestibilidade da energia da ração.

Os efeitos positivos das enzimas exógenas sobre a digestibilidade dos nutrientes da ração, segundo Bedford (2000), devem-se à modificação do local em que ocorre a digestão do amido e da proteína para a região anterior do trato digestório. Tal fato diminui a competição com as bactérias colonizadoras da região distal do trato gastrintestinal, aumentando a eficiência de utilização do alimento pelo animal.

Apesar do volume significativo de informações relacionadas à ação de enzimas exógenas sobre a digestibilidade das frações nutritivas da dieta para algumas espécies de monogástricos, o número de pesquisas com peixes é incipiente. Portanto, fazem-se necessários estudos acerca dos efeitos fisiológicos, morfológicos e os mecanismos de ação dessas enzimas com diferentes espécies de peixes cultiváveis.

Conclui-se que a adição de complexo enzimático contendo lipase, carboidrase e protease, em rações práticas à base de milho e soja para a tilápia-do-nilo, melhora significativamente $\mathrm{o}$ coeficiente de digestibilidade aparente da proteína bruta, do extrato etéreo, do carboidrato e da energia bruta.

\section{AGRADECIMENTOS}

À indústria Supre Mais Produtos Bioquímicos Ltda. pelo apoio científico. 


\section{REFERÊNCIAS BIBLIOGRÁFICAS}

BEDFORD, M.R. Exogenous enzymes in monogastric nutrition - their current value and future benefits. Anim. Feed Sci.Technol., v.86, p.1-13, 2000.

BEDFORD, M.R. Mechanism of action and potential environmental benefits from the use of feed enzymes. Anim. Feed Sci. Technol., v.53, p.145-155, 1995.

BOOTH, M.A.; ALLAN, G.L.; EVANS, A.J. et al. Effects of steam pelleting or extrusion on digestibility and performance of silver perch Bidyanus bidyanus. Aquac. Res., v.33, p.11631173, 2002.

BREMER NETO, H.; GRANER, C.A.F.; PEZZATO, L.E. et al. Determinação de rotina do crômio em fezes, como marcador biológico, pelo método espectrofotométrico ajustado da 1,5difenilcarbazida. Cienc. Rural, v.25, p.691-697, 2005.

CAVERO, B.A.S. Uso de enzimas digestivas exógenas na alimentação de juvenis de pirarucu Arapaima gigas (Cuvier, 1982). 2004. 79f. Tese (Doutorado) - Instituto Nacional de Pesquisas da Amazônia, Universidade Federal do Amazonas, Manaus.

CHAMPE, P.C.; HARVEY, R.A. Enzimas. In: Bioquímica ilustrada. 2.ed. São Paulo: Artes Médicas, 1989. p.53-66.

CHO, C.Y., COWEY, C.W., WATANABE, T. Finfish nutrition in Asia: methodological approaches to research and development. Otawa: IDRC, 1985. 154p.

CLASSEN, H.L. Cereal grain starch and exogenous enzymes in poultry diets. Anim. Feed Sci. Technol., v.62, p.21-27, 1996.

GARCIA, E.R.M.; MURAKAMI, A.E.; BRANCO, A.F. et al. Efeito da suplementação enzimática em rações com farelo de soja e soja integral extrusada sobre a digestibilidade de nutrientes, o fluxo de nutrientes na digesta ileal e o desempenho de frangos. Rev. Bras. Zootec., v. 29, p.1414-1426, 2000.
MAYNARD, L.A.; LOOSLY, J.K. Nutrição animal. Rio de Janeiro: McGraw Hill, 1966. $550 \mathrm{p}$.

OFFICIAL methods of analysis. 16.ed. Arlington, VA: AOAC, 1995.

PENZ JÚNIOR, A.M. Enzimas em rações para aves e suínos. In: SIMPÓSIO DE ADITIVOS NA PRODUÇÃO DE RUMINANTES E NÃO RUMINANTES, 1998, Botucatu, SP. Anais... Botucatu: SBZ, 1998. p.165-178.

PEZZATO, L.E.; BARROS, M.M.; FRACALOSSI, D.M. et al. Nutrição de peixes. In: CYRINO, J.E.P.; URBINATI, E.C.; FRACALOSSI, D.M. et al. (Ed.). Tópicos especiais em piscicultura de água doce tropical intensiva. São Paulo: Aquabil, 2004. p.75-172.

POPMA, T.J.; GREEN, B.W. Sex reversal of tilapia in earthen ponds. Auburn, AL: Alabama Agricultural Experiment Station, 1990. 15p.

SALANOVA, M.S. The use of enzymes to improve the nutritional value of corn-soy diets for poultry and swine. In: SIMPÓSIO LATINOAMERICANO DE NUTRIÇÃO DE SUÍNOS E AVES, 1996, Campinas, SP. Anais... Campinas: CBNA, 1996. p.1-13.

STONE, D.A.J.; ALLAN, G.L.; ANDERSON, A.J. Carbohydrate utilization by juvenile silver perch Bidyanus bidyanus (Mitchell). II. Digestibility and utilization of starch and its breakdown products. Aquac. Res., v.34, p.109121, 2003.

TUNG, P.H.; SHIAU, S.Y. Effects of meal frequency on growth performance of hybrid tilapia, Oreochromis niloticus x O. aureus, fed different carbohydrate diets. Aquaculture, v.92, p.343-350, 1991.

VENS-CAPPELL, B. The effects of extrusion and pelleting of feed for trout on the digestibility of protein, amino acids and energy and on feed conversion. Aquac. Eng., v.3, p.71-89, 1984.

YIN, Y.-L.; BAIDOO, S.K.; JIN, L.Z. et al. The effect of different carbohydrase and protease supplementation on apparent (ileal and overall) digestibility of nutrients of five hulless barley varieties in young pigs. Livest. Prod. Sci., v.71, p.109-120, 2001. 